\title{
Experimental Study of Seismic Reduced Performance of Series Isolation System
}

\author{
Zhongtie WU \\ School of Civil Engineering \\ Northwest University for Nationalities \\ Lanzhou730030, China \\ E-mail: wuzhongtie1982@163.com
}

\begin{abstract}
In order to study the seismic reduced performances (SRP) of series isolation systems (SIS) under multi-dimensional seismic excitation (MDSE), a series of shaking table tests had been conducted for the SIS model. The two groups of seismic waves, including the near fault ground motion and far fault ground motion were firstly chose from the Chichi earthquakes as the input. The responses of SIS under the different seismic waves were predicted by response spectrum method. The paper discussed the effect of earthquake intensity on SRP of SIS under different input patterns, and further analyzed the effect of near fault ground motion and far fault ground motion on the SRP, and compared to the predicted results. The results show that, compared to near fault ground motion, the seismic reduced ratio (SRR) of SIS is better under the far fault ground motion. The SRR of SIS increases with increasing the earthquake intensity, but it is obvious under near fault ground motion. The test results are consisted with the predicted results. The SRRs are small for the different shaking table tests, so the SRP of SIS is better. Moreover, the SRP under 2-dimensional seismic excitation is consistent with that under 3-dimensional seismic excitation with increasing the earthquake intensity.
\end{abstract}

Keywords-series isolation system; seismic reduced performance; shaking table test; response spectrum method; earthquake intensity; near fault ground motion; multidimensional seismic excitation

\section{INTRODUCTION}

With the rapid population increase and the construction of isolated structure is gaining acceptance. Series isolated structure is widely applied in isolated structure including isolated buildings and isolated bridges. SIS is an important part of series isolated structure. Its SRP is discussed under the MDSE. The theoretical and experimental research on the SIS is rare in domestic and foreign research works. Zhou Xiyuan et al. (1999) established an analysis model of series isolation system based on the Harings and Gent researches[1]. DU Yongfeng et al. (2011) did the theoretical analysis by matrix transfer method and static experiment for scale model of SIS, and analyzed the collapse of series isolation structure under the MDSE[2, 3]. WU Yingxiong et al. studied the dynamic properties and performance analysis of isolation technology for a first-floor isolation structure[4]. Many shaking table tests for isolation structure were carried out and some good conclusions were obtained[5 9]. On the basis of previous research, this paper aims at investigating the performance of SIS in the isolated structure to do shaking table tests under the 2-dimensional seismic excitation (2DSE) and 3-dimensional seismic excitation (3DSE) and analyzed its SRP using the SRR and discussed the influence of earthquake intensity on its SRP, and gave some good conclusions.

\section{Design Of Test Model}

The test model is shown in Fig. 1. It consists of one plate and four series isolation systems composed of lead rubber bearing (LRB) and reinforcement concrete (RC) column. The upper total weight is up to 10t. The parameters of LRB, $\mathrm{RC}$ column and concrete plate are shown in Tab. 1 and Tab. 2 , respectively.

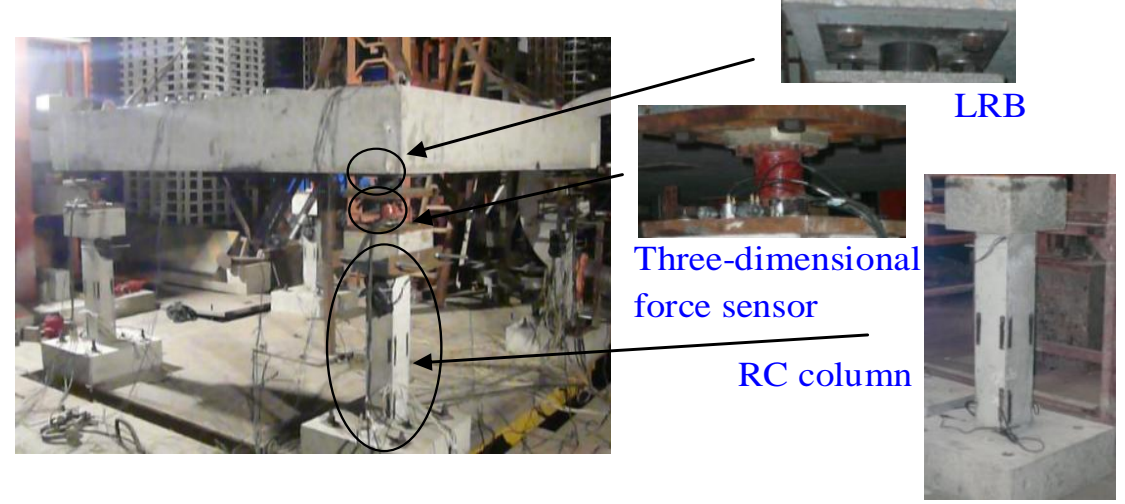

Figure 1. Test model of SIS. 
TABLE I.

PARAMETERS OF LRB

\begin{tabular}{|c|c|c|c|c|c|c|c|}
\hline Type & $\begin{array}{c}\mathrm{D}_{1} \\
(\mathbf{m m})\end{array}$ & $\begin{array}{c}\mathbf{D}_{0} \\
(\mathbf{m m})\end{array}$ & $\begin{array}{c}\mathbf{l}_{\mathbf{r}} \\
(\mathbf{m m})\end{array}$ & $\begin{array}{c}\mathbf{P}_{\mathbf{b}} \\
(\mathbf{M P a})\end{array}$ & $\begin{array}{c}\mathbf{Q}_{\mathrm{d}} \\
(\mathbf{k N})\end{array}$ & $\begin{array}{c}\mathbf{K}_{\mathrm{d}} \\
(\mathrm{kN} / \mathbf{m m}) \\
\end{array}$ & $\begin{array}{c}\mathbf{K}_{\mathrm{eq}} \\
(\mathbf{k N} / \mathbf{m m}) \\
\end{array}$ \\
\hline LRB90 & 90 & 15 & 18 & $4-5$ & 1.409 & 0.139 & 0.217 \\
\hline
\end{tabular}

TABLE II. PARAMETERS OF RC COLUMN AND PLATE

\begin{tabular}{|c|c|c|c|c|c|c|c|c|c|c|}
\hline \multirow[b]{2}{*}{ Type of materials } & \multicolumn{4}{|c|}{ Materials performance } & \multicolumn{3}{|c|}{ RC column } & \multicolumn{3}{|c|}{ Concrete plate } \\
\hline & $\begin{array}{c}E \\
(\mathbf{M P a})\end{array}$ & $v$ & $\begin{array}{c}f t \\
(\mathbf{M P a})\end{array}$ & $\begin{array}{c}f c \\
(\mathbf{M P a})\end{array}$ & $\begin{array}{c}L_{c} \\
(\mathbf{m m})\end{array}$ & $\begin{array}{c}\boldsymbol{B}_{\boldsymbol{c}} \\
(\mathbf{m m})\end{array}$ & $\begin{array}{c}\boldsymbol{H}_{\boldsymbol{c}} \\
(\mathbf{m m})\end{array}$ & $\begin{array}{c}\begin{array}{c}L_{p} \\
(\mathbf{m m})\end{array} \\
\end{array}$ & $\begin{array}{c}B_{p} \\
(\mathbf{m m})\end{array}$ & $\begin{array}{c}\boldsymbol{H}_{p} \\
(\mathbf{m m})\end{array}$ \\
\hline concrete & 30000 & 0.2 & 1.43 & 14.3 & & & & & & \\
\hline Longitudinal bar & 200000 & 0.3 & 300 & 300 & 150 & 150 & 1000 & 2800 & 2800 & 400 \\
\hline Stirrup & 200000 & 0.3 & 270 & 270 & & & & & & \\
\hline
\end{tabular}

Note: E-elastic modulus, v-poisson ratio, $\mathrm{f}_{\mathrm{t}}$-tensile strength, $\mathrm{f}_{\mathrm{c}}$-com
$\mathrm{L}_{\mathrm{p}}, \mathrm{B}_{\mathrm{p}}, \mathrm{H}_{\mathrm{p}}$-length, width and height of concrete plate respectively.

\section{EQUIVALENT PERIOD OF TEST MODEL}

The SIS consists of lead rubber bearing and RC column, so its equivalent horizontal stiffness can be approximately obtained by the following formula.

$$
K_{\text {eqSIS }}=K_{\text {eqLRB }} \frac{K_{\text {eqRC }}}{K_{\text {eqLRB }}+K_{\text {eqRC }}}
$$

Where, $K_{\text {eqsis }}$ is the equivalent horizontal stiffness of SIS, and $K_{\text {eqLRB }}$ is the equivalent horizontal stiffness of LRB, and $K_{\text {eqRC }}$ is the equivalent horizontal stiffness of RC column, $K_{\text {eqLRB }}$ and $K_{\text {eqRC }}$ are computable by (2) and (3), respectively.

$$
\begin{gathered}
K_{\text {eqLRB }}=K_{\mathrm{d}}+\frac{Q_{\mathrm{d}}}{d} \\
K_{\mathrm{eqRC}}=\frac{3 E_{\mathrm{C}} I_{\mathrm{C}}}{L^{3}}
\end{gathered}
$$

Where, $d$ is the horizontal displacement of LRB, $E_{C}$ is the elastic modulus of concrete, $I_{C}$ is the moment of inertia of RC column.

Its equivalent period can be obtained by (4).

$$
T_{\text {eqSIS }}=2 \pi \sqrt{\frac{M}{K_{\text {eqSIS }}}}
$$

Where, $T_{\text {eqsis }}$ is the equivalent period of SIS, $M$ is the upper total weight of SIS.

The displacement response of SIS is different under the seismic waves. The horizontal stiffness of SIS varies with its shear deformation, then, the period of SIS changes with the deformation. The equivalent period of SIS can be calculated by (4). The results are listed in the tab. 3. It can be seen from the tab. 3. The period increases with the increasing of the shear deformation and ranges from 0.5$0.8 \mathrm{~s}$ when the shear deformation varies from $25 \%-250 \%$.

TABLE III. THE EQUIVALENT PERIOD OF SIS

\begin{tabular}{cccccc}
\hline $\begin{array}{c}\text { shear } \\
\text { deformation }(\%)\end{array}$ & $\mathbf{2 5}$ & $\mathbf{5 0}$ & $\mathbf{1 0 0}$ & $\mathbf{2 0 0}$ & $\mathbf{2 5 0}$ \\
\hline$T_{\mathrm{eq}}(\mathrm{S})$ & 0.538 & 0.636 & 0.723 & 0.788 & 0.804 \\
\hline
\end{tabular}

\section{Selection and Analysis of Seismic Waves,}

The two groups of seismic waves, which are named CC1 and $\mathrm{CC} 2$, are selected from the Chichi earthquake in this paper, and the $\mathrm{CC} 1$ has three components and the CC2 has two components. There are two input patterns in shaking table test, including two components (X direction and $\mathrm{Y}$ direction) and three components (X direction and $\mathrm{Y}$ direction and $\mathrm{Z}$ direction). The parameters of seismic waves and input patterns are shown in Tab. 4 and Tab. 5, respectively. The seismic waves with the peak values of 100 gal, $150 \mathrm{gal}, 200 \mathrm{gal}, 300 \mathrm{gal}$ and $400 \mathrm{gal}$ are adopted as excitations for shaking table tests. Acceleration time history of seismic waves and the response spectra are shown in Fig. 2 and Fig. 3, respectively. It can be seen in Fig. 2 that the acceleration of $\mathrm{CC} 1$ is big and appears relatively concentrated. However, the acceleration of CC2 is small and appears relatively discrete. It can be seen from Fig. 3, when the peek acceleration of $\mathrm{CC} 1$ in the response spectra appears, the period is at $0.35 \mathrm{~s}$, and the period of its dominant effect ranges from $0.3 \mathrm{~s}$ to $1.5 \mathrm{~s}$. When the peek acceleration of CC2 in the response spectra appears, the period is at $0.14 \mathrm{~s}$, and the period of its dominant effect ranges from $0.1 \mathrm{~s}$ to $0.8 \mathrm{~s}$. The equivalent period of SIS mainly distributes at the range of $0.5 \mathrm{~s}-0.8 \mathrm{~s}$, the time step of nature seismic waves is scaled from $0.02 \mathrm{~s}$ to $0.01 \mathrm{~s}$ in the shaking table test, and natural period of response spectra has the same change. The equivalent period of SIS is at range of the dominant effect of 
near fault ground motion, therefore, it can be predicted that its seismic response of SIS is larger, and its seismic reduced effect is lower.

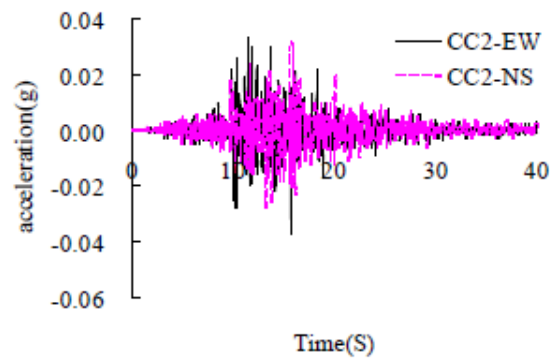

(b)

(a)

Figure 2. Time history of acceleration: (a) CC1, (b) CC2.

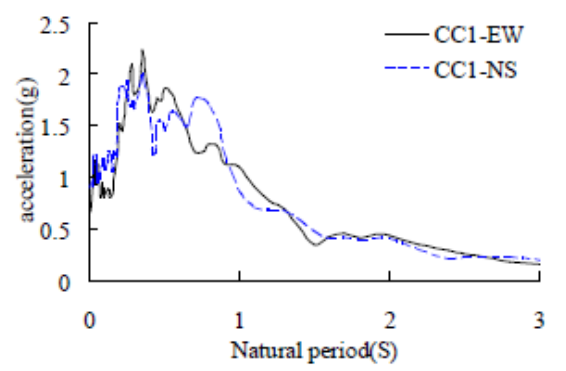

(a)

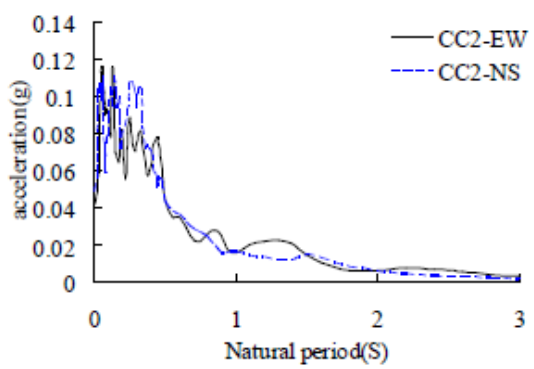

(b)

Figure 3. Response spectra (5\% damping ration): (a) $\mathrm{CC} 1$, (b) $\mathrm{CC} 2$.

TABLE IV. PARAMETERS OF SEISMIC WAVES

\begin{tabular}{cccccccc}
\hline $\begin{array}{c}\text { Earthquake } \\
\text { waves }\end{array}$ & station & Year & Magnitude & $\begin{array}{c}\text { Rupture distance } \\
\mathbf{( k m )}\end{array}$ & \multicolumn{3}{c}{ Peak acceleration $(\mathrm{g})$} \\
\cline { 5 - 8 } CC1 & CHY028 & 1999 & 7.62 & 3.1 & $\boldsymbol{E W}$ & $\boldsymbol{U D}$ \\
CC2 & CHY028 & 1999 & 5.9 & 46 & 0.821 & 0.653 & 0.337 \\
\hline
\end{tabular}

TABLE V. INPUT PATTERN

\begin{tabular}{|c|c|c|c|}
\hline \multirow{2}{*}{ No. } & \multirow{2}{*}{ Main direction } & \multicolumn{2}{|c|}{ Input pattern(Input direction) } \\
\hline & & $2 D S E(X+Y)$ & $3 D S E(X+Y+Z)$ \\
\hline 1 & CC2-NS & $\mathrm{CC} 2-\mathrm{NS}+\mathrm{CC} 2-\mathrm{EW}$ & - \\
\hline 2 & CC2-EW & $\mathrm{CC} 2-\mathrm{EW}+\mathrm{CC} 2-\mathrm{NS}$ & - \\
\hline 3 & CC1-NS & CC1-NS+CC1-EW & $\mathrm{CC} 1-\mathrm{NS}+\mathrm{CC} 1-\mathrm{EW}+\mathrm{CC} 1-\mathrm{UD}$ \\
\hline 4 & CC1-EW & $\mathrm{CC} 1-\mathrm{EW}+\mathrm{CC} 1-\mathrm{NS}$ & $\mathrm{CC} 1-\mathrm{EW}+\mathrm{CC} 1-\mathrm{NS}+\mathrm{CC} 1-\mathrm{UD}$ \\
\hline
\end{tabular}

\section{ANALYSIS ON THE SRP OF SIS}

In order to study the SRP of SIS, the SIS model has been carried out through the shaking table test. The effect of main factors on the SRP of SIS, including the near fault ground motion, earthquake intensity and mult-dimensional seismic excitation is analyzed. The accelerations of the three key positions are chosen from the testing data, which include the surface of shaking table, the top of concrete plate. The SRP of SIS is analyzed by using the SRR $\alpha$ calculated by (5) and the amplification coefficient $\beta$ calculated by (6). Where $S_{a}$ is the peak value of absolute acceleration obtained from the top of concrete plate and $\mathrm{u}_{\mathrm{g}}$ is the peak value of absolute acceleration obtained from the surface of shaking table.

$$
\beta=\frac{S_{\mathrm{a}}}{u_{\mathrm{g}}}
$$




$$
\alpha=1-\beta
$$

The related curves of earthquake intensity and SRR of BD under the 2DSE are shown in Fig. 4. It can be seen that the SRR of SIS under the far fault ground motion is better than that under the near fault ground motion, and the value of SRR under the far fault ground motion is approximately 2 to 1.3 times at the range from $0.1 \mathrm{~g}$ to $0.5 \mathrm{~g}$. It is consisted with the analysis results based on the response spectrum method. In the meantime, the SRR increases with increasing earthquake intensity and change laws of SRR under the near fault ground motion are much clearer. It shows that SRP is better with increasing the earthquake intensity and it is not the same for different ground motions. Moreover, it is clear that the SRR of SIS is different for the different components of seismic wave at the same station. As shown in Fig. 5. It illustrates that four main directions in all input patterns are CC2-NS, CC2-EW, CC1-NS and CC1-EW, respectively. The average value of SRR is $0.7,0.72,0.49$ and 0.43 in turn, and the biggest difference is $0.036,0.028,0.204$ and 0.162 in turn. Obviously, the SRR under the near fault ground motion is less than that under the far fault ground motion, and its SRP is worse. It shows that the SRP is not only affected by earthquake intensity, but also by the characteristics of seismic wave.

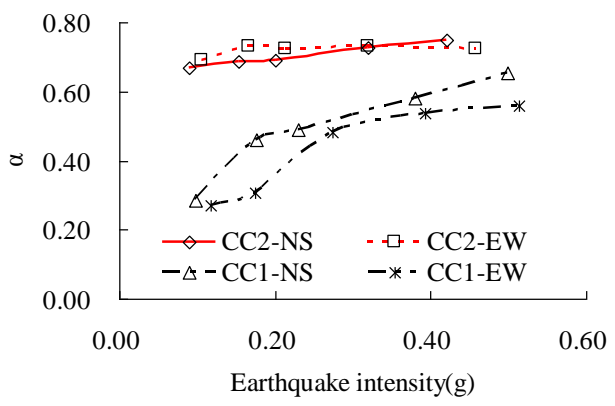

Figure 4. Related curves between SRR $\alpha$ and earthquake intensity under the 2DSE.

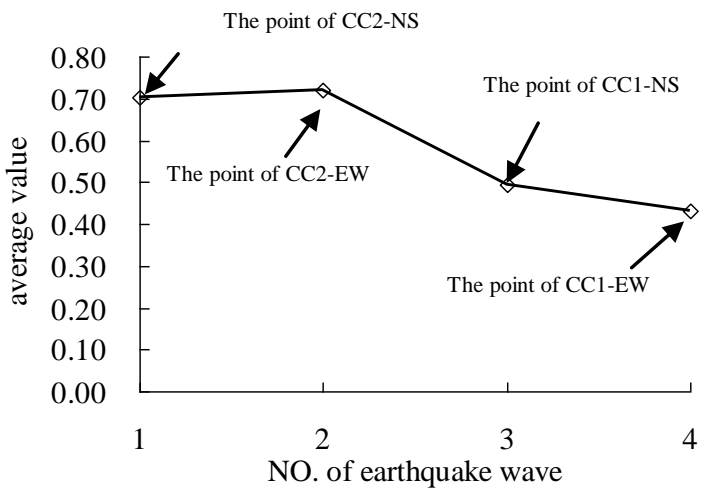

Figure 5. The average value of SRR $\alpha$ under the 2DSE.

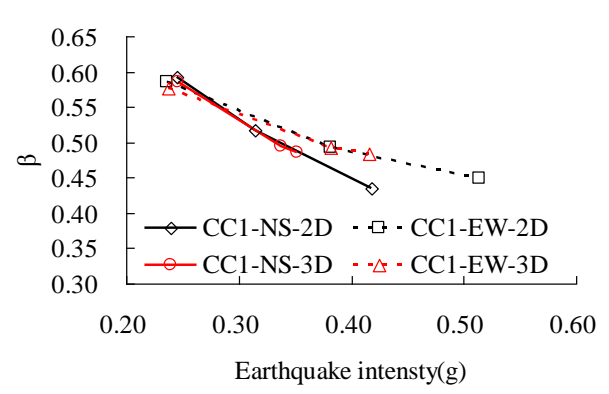

Figure 6. Amplification coefficient $\beta$ of BD for different input patterns

Fig. 6 shows the related curves between amplification coefficient and earthquake intensity of key positions BD under different input patterns of $\mathrm{CC} 1$. The amplification coefficient of BD decreases with increasing the earthquake intensity under the 2DSE and 3DSE. The change laws of curves are basically the same. The curves of the amplification coefficient are closed, but it is slightly lower under 3DSE. The SRP is better with increasing the earthquake intensity under the 3DSE.

\section{CONCLUSIONS}

The following conclusions are obtained from the test analysis.

1) The SRR of SIS is greatly affected by the different seismic waves. The SRP of SIS under the near fault ground motion is worse than that under the far fault ground motion.

2) The earthquake intensity has great influence on the seismic reduced performance of SIS, and SRR increases with increasing earthquake intensity and SRP is better. And it is more obvious for the near fault ground motion.

3) The effect of multi-dimensional seismic excitation on SRP of SIS is not clear, and the two kinds of curves are very close. But the SRR under the 3DSE is slightly higher than that under the 2DSE.

4) The equivalent period of SIS mainly distributes at a range of natural period that the effect of near fault ground motion is significant. Therefore, its SRR is less than that under far fault ground motion. And the SRP under the far fault ground motion is better. These results are consistent with the results obtained from response spectra analysis.

5) The SRP also is affected by the characteristics of seismic wave, and it should be further studied.

\section{ACKNOWLEDGMENT}

The study presented in this paper was supported by the Fundamental Research Funds for the Central Universities (FRFCUC) (Grant No. 31920150019 and 31920150020) and Talent Introduction of Scientific Research Project of Northwest University for Nationalities of China (Grant No. xbmuyjrc201405). The support is gratefully acknowledged.

\section{REFERENCES}

[1] Zhou Xiyuan, Han Miao, "Horizontal rigidity coefficient of the serial system of rubber bearing with column," Journal of Vibration Engineering. Vol.12 (2) (1999), p.159-165. 
[2] DU Yong-feng, ZHU Qiankun, LI Hui, "Analysis of large deformation behavior of series isolation system and its experimental verification, "Journal of Vibration and Shock. Vol.30 (11) (2011), p. 236-239.

[3] DU Yong-feng, WANG Xiao-hu, "Collapse simulation of the serial isolation structure subjected to multi-dimensional earthquake, "Earthquake Resistant Engineering and Retrofitting. Vol.34 (6) (2012), p. 50-54.

[4] WU Ying-xiong, QI Ai, YAN Xue-yuan, "Study on test of dynamic properties for a first-floor isolation structure, "Journal of Earthquake Engineering and Engineering Vibration. Vol.31 (6) (2011), p. 147152 .

[5] JIN Jian-min, TAN Ping, ZHOU Fu-lin, "Shaking table tests for a mid-story isolation structure with shock absorber, " Journal of Earthquake Engineering and Engineering Vibration. Vol.31(6) (2012), p. 104-108.
[6] XU ZhaoDong, ZENG Xiao, WU KeYi, LI AiQun, XU QingYang, "Horizontal shaking table tests and analysis on structures with multidimensional earthquake isolation and mitigation devices, "Sci China Ser E-Tech Sci. Vol.52 (7) (2009), p. 2009-2016.

[7] F. Mazza, A. Vulcano, "Nonlinear response of RC framed buildings with isolation and supplemental damping at the base subjected to near-fault earthquakes, " Journal of Earthquake Engineering. Vol.13 (5) (2009), 690-715.

[8] E. Takaoka, Y. Takenaka, A. Nimura, "Shaking table test and analysis method on ultimate behavior of slender base-isolated structure supported by laminated rubber bearings, " Earthquake Engineering \& Structural Dynamics. Vol.40 (5) (2011), p. 551-570.

[9] J. Sanchez, A. Masroor, G. Mosqueda, K. Ryan, "Static and dynamic stability of elastomeric bearings for seismic protection of structures, " Journal of Structural Engineering. Vol.139 (7) (2013), p. 1149-1159. 